\title{
A STUDY ON INTRAVAGINAL MISOPROSTOL FOR INDUCTION OF LABOUR
}

\author{
Ahanthembi Sanaton, Ng Indrakumar Singh, S. Thoibahenba
}

1. Assistant Professor. Department of Obstetrics \& Gynaecology, Jawaharlal Nehru Institute of Medical Sciences, Porompat, Imphal.

2. Professor \& Head. Department of Obstetrics \& Gynaecology, Jawaharlal Nehru Institute of Medical Sciences, Porompat, Imphal.

3. Assistant Professor. Department of Obstetrics \& Gynaecology, Jawaharlal Nehru Institute of Medical Sciences, Porompat, Imphal.

\section{CORRESPONDING AUTHOR:}

Dr. S. Thoibahenba Singh,

Chingamathak Pishum Leirak, Imphal - 795001,

Manipur.

E-mail: thoibas@gmail.com

\begin{abstract}
Misoprostol, a synthetic $\mathrm{PGE}_{1}$, analogue may be used for induction of labour. It is a preliminary study to evaluate the efficacy and safety of intravaginal insertion of misoprostol 50 ugm tablet for induction of labour. A total of 110 consecutive cases of singleton term pregnancy with cephalic presentation having Bishops cervical score $\leq 4$ were included. Cases of CPD, placenta praevia, previous uterine scars and twin conceptions were excluded. Ninety-six women had vaginal delivery and 14 cases had caesarean deliveries. Average induction delivery interval was $10.8 \pm 4.8$ hours. Apgar score of newborn at 1 minute was $8.86 \pm 0.735$. Induction of labour with single dose of $50 \mu \mathrm{gm}$ of misoprostol vaginally is effective as other inducing agents with no obvious side-effects to both mothers and newborns
\end{abstract}

KEYWORDS: Misoprostol; Bishops Score

INTRODUCTION: Tablet misoprostol is relatively cheap and easy to administer vaginally and may be as effective as other labour induction agents and with minimal side effects when cases are monitored properly.

There are many armamentarium for induction of labour including intra-venous infusion of Oxytocin, intra-cervical application of prostaglandins etc. Misoprostol, a synthetic PGE 1 analogue when inserted intravaginally has been used for termination of pregnancy at Regional Institute of Medical Sciences Hospital. However well designed clinical study of this drug for induction of labour had not been conducted in this part of the globe even though it had been tried in a few cases sporadically at this Institute with no significant harmful effects. Hence with prior approval from Institutional Ethics Committee, this preliminary study had been undertaken before a systemic RCT had been contemplated.

MATERIALS AND METHODS: During the period, March 2003 to April 2003, all consecutive pregnant women requiring induction of labour in our Obstetric unit with singleton pregnancy and cephalic presentation at Bishop's Cervical Score less than or equal to 4 are included. Subjects with Cephalo-pelvic disproportion (CPD), placenta praevia, previous LSCS, multiple pregnancy and abnormal foetal presentations are excluded and a total of 110 subjects are enrolled after their informed consent. A single dose of $50 \mu \mathrm{gm}$ misoprostol tablets are inserted 
per vaginal, deep in the posterior vaginal fornix at the time of initiation of induction of labour. Patients were monitored hourly for uterine contraction, foetal heart rate and maternal vital signs. ARM (artificial rupture of membrane) was done when cervix is $4-5 \mathrm{cms}$ dilated and augmentation with oxytocin as and when there is less than 3 good uterine contractions over a period of 10 minutes. The induction to delivery interval and route of delivery were noted. Bishops score, Apgar score and maternal as well as foetal/neonatal complications are noted. Data are analysed using simple mathematical calculations.

RESULTS: Results are shown in Tables I-IX. Out of 110 women included in the study 96 cases had vaginal delivery and 14 cases delivered by LSCS. Out of 96 subjects delivered vaginally, 54 subjects are augmented with minimal dose of Oxytocin infusion. The average induction delivery interval was $10.8 \pm 4.8$ hours. Apgar score at 1 minute was $8.86 \pm 0.735$. Few patients had minor complications like $1^{\circ}$ perineal tear, cervical tear and mild PPH. Foetal distress was observed in 3 cases. There was no maternal mortality or neonatal death and no neonate is admitted in the neonatal ICU.

DISCUSSIONS: Single dose of $50 \mu \mathrm{gm}$ of misoprostol is effective for induction of labour. It is stable at room temperature, rapidly absorbed orally and vaginally. In vaginal administration plasma concentration rises gradually and reaches maximum level between 60-120 minutes and declines slowly to an average of 61 percent of peak level by 240 minutes. Bio availability of drug is 3 times higher. Zeiman $\mathrm{M}$, Fong $\mathrm{SK}$ et al, described the pharmacokinetics and pharmacodynamics of misoprostol and its effects on uterine activities. Costa SH, Vessey MP reported the use of misoprostol in illegal abortions. Evita Fernandez and Suseela Vavilala studied the efficacy of Misoprostol for induction of labour at term and estimated the induction to delivery time to be $10.34 \pm 1.14$ hrs. R.Surekha, Lavanya Rai and MS Urala 2001 studied single dose Misoprostol for induction of labour in 86 women and found mean induction to vaginal delivery interval was $9.09 \pm 4$ hours. Their finding is comparable to that of our study. B.S.Krishnamma, A.Sundari and I.Sunila Naidu studied induction of labour with Misoprostol in 150 cases and found $42.6 \%$ delivered normally without any drug for acceleration, another $30 \%$ delivered vaginally with augmentation either with PG tab or oxytocin. The induction delivery internal was approximately 12-14 hours. This finding corroborates with our finding of 42 deliveries with misoprostol only and 54 with misoprostol and oxytocin augmentation. These studies do not show significant maternal and foetal/neonatal side-effects except benign foetal arrhythmias. Like-wise our study does not show any clinically significant maternal and foetal/neonatal side-effects.

CONCLUSION: Our study shows that a single dose of 50 ugm of intravaginal misoprostol could be a good alternative for induction of labour with minimal side-effects. However, better designed studies comparing it with other well-established labour induction methods are required before generalizing and recommending the use of intravaginal misoprostol 50 ugm for induction of labour.

\section{REFERENCES:}

1. Zeiman M, Fong SK, Benowitz NL, Banskter D, Darney PP.

Misoprostol: Pharmacokinetic profiles, effect on the uterus \& side effects. Obstet Gynaecol 1997; 90:88. 
2. Costa SH, Vessey MP. Misoprostol and illegal abortions in Rio De Janeiro, Brazil. Lancet 1993; 341:1258-61.

3. Evita Fernandez and Suseela Vavilala. Misoprostol-A Miracle Drug? Obs. \& Gynae,Today 2001;9:530-534.

4. R Surekha,Lavanya Rai and RS Urala. Single Dose Misoprostol for Induction of Labour. Obs. and Gynae 2001;VI (2):95-97.

5. B.S. Krishnamma, A. Sundari, I.Sunila Naidu. Evaluation of a New Drug Misoprostol - For Induction of Labour. J Obst. \& Gyn. of India 2002;

52:64-66.

TABLE-I AGE \& PARITY DISTRIBUTION

\begin{tabular}{ccccc}
\hline Age in years & $20-25$ & $26-30$ & $31-35$ & total \\
No. & 52 & 42 & 16 & 110 \\
P0 & 18 & 22 & 10 & 50 \\
P1 & 9 & 13 & 13 & 35 \\
P2 & 2 & 10 & 13 & 25 \\
\hline
\end{tabular}

TABLE - II INDICATION FOR INDUCTION

\begin{tabular}{cccccccc}
\hline & Parity & PROM & PDP & PDP with PROM & TP & PET & PIH \\
\hline & Primi & 25 & 14 & 1 & 7 & 3 & - \\
& Multi & 22 & 13 & 1 & 17 & 6 & 1 \\
Total & & 47 & 27 & 2 & 24 & 9 & 1 \\
Percentage & & 42.7 & 24.5 & 1.8 & 21.8 & 8.18 & 0.91 \\
\hline
\end{tabular}

TABLE - III BISHOP SCORE AT O AND 4 HOURS

\begin{tabular}{cc}
\hline TIME & BISHOP SCORE \\
\hline 0 hours & $3.436 \pm 0.736$ \\
4 hours & $5.773 \pm 2.204$ \\
\hline
\end{tabular}

TABLE - IV MODE OF DELIVERY

\begin{tabular}{lll}
\hline & Number of patients & percentage \\
\hline Spontaneous vaginal delivery & 88 & 80 \\
Instrumental delivery & 8 & 7.2 \\
Caesarean Section & 14 & 12.72 \\
Total & 110 & \\
\hline
\end{tabular}

MODE OF VAGINAL DELIVERY

Vaginal delivery $\quad-96$

Misoprostol only $\quad-42$

Misoprostol with oxytocin - 54 
TABLE -V DISTRIBUTION OF NO OF CASES WITH RESPECT TO INDUCTION DELIVERY INTERVAL (HOURS)

\begin{tabular}{ccc}
\hline Induction delivery interval ( in hours ) & Number of pregnant woman & Percentage \\
\hline Within 6 hours & 20 & 21.3 \\
$\mathbf{6}$ - 12 hours & 44 & 46.8 \\
$\mathbf{1 2}$ - 24 hours & 30 & 31.9 \\
Total ( within 24 hours ) & 94 & 97.9 \\
After 24 hours & 2 & 2.1 \\
Total & 96 & 100 \\
\hline
\end{tabular}

TABLE VI PARITY WISE INDUCTION DELIVERY INTERVAL IN HOURS

\begin{tabular}{cccc}
\hline \multicolumn{3}{c}{ Time interval (mean \pm S.D.) in hour } & Average \\
mean \pm S.D \\
$\mathbf{P}_{\mathbf{0}}$ & $\mathrm{P}_{1}$ & $\mathrm{P}_{2}$ & \\
$\mathbf{1 1 . 3 7} \pm \mathbf{5 . 9 7}$ (39) & $10.73 \pm 8.47$ (33) & $10.10 \pm 6.39(24)$ & $10.833 \pm 4.856$ \\
\hline
\end{tabular}

Figure within the parenthesis indicate no of cases

TABLE - VII DISTRIBUTION OF CAESARIAN SECTION

\begin{tabular}{ccccc}
\hline \multicolumn{4}{c}{ Parity } & Percentage \\
\cline { 1 - 4 } $\mathbf{P}_{\mathbf{0}}$ & $\mathrm{P}_{1}$ & $\mathrm{P}_{2}$ & Total & \\
$\mathbf{1 1}$ & 2 & 1 & 14 & 12.72 \\
\hline
\end{tabular}

Percentage calculated with 110 (no of patients)

TABLE -VIII NUMBER AND VARIOUS INDICATIONS FOR CAESARIAN SECTIONS

\begin{tabular}{cccccc}
\hline & $\begin{array}{c}\text { Foetal } \\
\text { distress }\end{array}$ & $\begin{array}{c}\text { Cervical } \\
\text { dystocia }\end{array}$ & $\begin{array}{c}\text { Persistent } \\
\text { Occiput posterior }\end{array}$ & Fail to respond & total \\
\hline & 03 & 04 & 04 & 03 & 14 \\
Percentage & 21.4 & 28.6 & 28.6 & 21.4 & 100 \\
\hline
\end{tabular}

TABLE - IX MATERNAL SIDE-EFFECTS

\begin{tabular}{|c|c|c|c|}
\hline EVENT & NO & $\%$ & REMARK \\
\hline Perineal tear & 2 & 2.1 & First degree tear \\
\hline Cervical tear & 6 & 6.3 & \\
\hline PPH & 9 & 9.3 & Managed conservatively \\
\hline Maternal death & 0 & 0 & \\
\hline
\end{tabular}

TABLE - X FOETAL/NEONATAL OUTCOME

\begin{tabular}{|c|c|c|c|}
\hline EVENT & NO & $\%$ & REMARK \\
\hline Foetal bradycardia & 3 & 2.7 & Delivered by LSCS \\
\hline Apgar Score (1min) & $8.86 \pm 0.735$ & & \\
\hline NICU admission & 0 & 0 & \\
\hline Foetal/Neonatal mortality & 0 & 0 & \\
\hline
\end{tabular}

